CATALAN REVIEW

Catalan Review

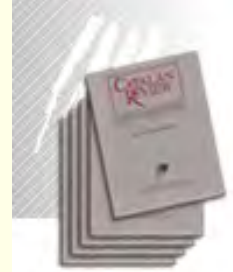

You are accessing the Digital Archive of the Catalan Review Journal.

By accessing and/or using this Digital Archive, you accept and agree to abide by the Terms and Conditions of Use available at http://www.nacs-

catalanstudies.org/catalan review.html

Catalan Review is the premier international scholarly journal devoted to all aspects of Catalan culture. By Catalan culture is understood all manifestations of intellectual and artistic life produced in the Catalan language or in the geographical areas where Catalan is spoken. Catalan Review has been in publication since 1986 .
NORTH

AMERICAN

CATALAN

SOCIETY
Esteu accedint a l'Arxiu Digital del Catalan Review

A l' accedir i / o utilitzar aquest Arxiu Digital, vostè accepta i es compromet a complir els termes i condicions d'ús disponibles a http://www.nacs-

catalanstudies.org/catalan review.html

Catalan Review és la primera revista internacional dedicada a tots els aspectes de la cultura catalana. Per la cultura catalana s'entén totes les manifestacions de la vida intel lectual i artística produïda en llengua catalana o en les zones geogràfiques on es parla català. Catalan Review es publica des de 1986.

\title{
La centralització de [o] àtona en català: del clotell al clatell Joan Veny
}

Catalan Review, Vol. XIII, number 1-2, (1999) p. 225-253 


\section{LA CENTRALITZACIÓ DE [O] ÀTONA \\ EN CATALÀ: DEL CLOTELL AL CLATELL}

\section{JOAN VENY}

\section{INTRODUCCIO}

Devem a Joseph Gulsoy diverses aportacions decisives en la solució de problemes de gramàtica històrica del català, especialment del que ell anomena "desenvolupaments secundaris, o, si es vol (...), lleis fonètiques menors" (Gulsoy 14). Aquest volum d'homenatge al meu estimat col'lega $\mathrm{i}$ amic em brinda l'oportunitat de tractar en honor seu les característiques d'un canvi fonètic que m'ha atret des de fa temps i al qual havia fet alguna referència breu, manifestant la meva voluntat de tractar-lo amb una certa extensió (Veny, Etimalogia 759 i Catxel, 472): es tracta de la centralització de la /o/ àtona, sobretot en posició inicial, esdevinguda $/ \partial /$ en català oriental $0 / a /$ en català occidental (tipus clotell $>$ clatell). Davant el nombre considerable de casos recollits, intentaré esbrinar si es tracta de fets esporàdics de la llengua $\mathrm{i}$ els seus dialectes o bé si ens trobem davant un mena de llei secundària, o menor, del català.

Divideixo el tema en els següents apartats:

A. Casos d' [o] pretònica:

I) amb assimilació a la tònica [a]:

a) inicial no absoluta;

b) interior;

2) amb dissimilació:
a) de la tònica tancada [o]:
b) de la tònica oberta [0];
c) de l'àtona [o];
d) per contacte.

3) Altres casos

B. Casos d' [o] inicial absoluta:

I) d'assimilació a la tònica [a];

2) de dissimilació:

a) de la tònica tancada [o];

b) de la tònica oberta [0];

c) de l'àtona [o].

3) Altres casos 
C. Casós de posició posttònica.

D. Casos de posició pretònica interna.

Parlo de centralització de $o$ referint-me al so del català preliterari o arcaic $[0]$ en posició àtona, mantingut en català occidental i mallorquí, i convertit en $/ u /$ en català oriental, entre els segles XV i XVI; incloc també casos de / $\mathrm{u} /$ àtona. La grafia dels mots amb a correspondrà a la vocal neutra /a/ del catală oriental i a /a/ del català occidental; el lector, doncs, trobarà grafies poc respectuoses amb la normativa com fredaluga 'fredeluga', patarc 'petarc', pató 'petó', fanèvol 'fenèvol', etc. De l'àrea geogràfica es deduirà si la forma és exclusivament occidental o oriental o de les dues àrees.

\section{A. $/ O /$ PRETÓNICA}

1. Casos d'assimilació a la tònica central /á/:

$[o] \ldots[$ á] $\rightarrow[ə] \ldots$ [á] (o [a]... [á])

a) Inicial no absoluta

ant, flamayre 'riu' (< flomaire, flumaire, derivat de flom, flum + el suf. -aire < -ARIU). Doc.: Regles d'esquivar vocables ("Evitar de dir flamayre per flumayre ") (ap. DCVB, s.v. flumaire)

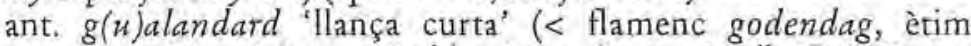
proposat per Diez i Meyer-Lübke i seguit per Moll [DCVB s.v. golondart ], però que no plau a Coromines). Doc:: a. I456 (Alomar 3ro311).

ant. lambard 'mestre d'obres' (< it. lombardo). Doc.: a. $138 \mathrm{I}$ (DCVB).

baldar -(se) 'gronxar-se' (< *boldar < vOLUTARE, DECat s.v. balder), Àrea: nord-occidental (DCVB). Introduït com a normatiu al DIEC, com el seu derivat baldador 'gronxador' (català nordoccidental [Dialectologia 256]).

barumballes, barrumballes 'flocs' (< baruballes < llat. BURBALiA) (DECat): València, Vinaròs (DCVB), Alacant (barambolles), Sant Mateu del Maestrat (barumballes), Albocàsser (barumballs) (ALDC). falgat (< folgat): Lloret (Fàbregas-Rebollo 243).

Mallorca.

farmatge (<formatge): Santanyi, Felanitx i alguns altres pobles de galafre (< golafre): valencià. Doc.: Millàs 25.

Ilabarro / llobarro (< derivat de llop + suf, augmentatiu -arro): Dénia (Cabrera 1997), Peníscola (enquesta 18.IV.1973).

llamàntol, llamanto 'crustaci Homarus gammarus' (< llomàntol 
[encara a Vilanova i la Geltrú, Cambrils, l'Ametlla de Mar, Sant Carles de la Ràpita, Peníscola, el Grau de Castelló, Borriana, LMP] < llobàntol < *logbantol < LUCOPANTERU 'onça, espècie de pantera' [DECat]). Àrea: Badalona, Maresme, València, Pollença (DCVB, LMP 722). Coromines atribueix al canvi al creuament amb llagosta, amb l'ajuda de l'assimilació. Llamàntol és mot normatiu.

llangant 'llomàntol' (< llongant): Rosselló, Cadaqués (Centelles 28I, Sala, DECat s.v. llomàntol).

navalla 'ganivet de fulla plegable, raor' (<novalla [encara a part de l'aragonès] < NOVACULA): franja oest del nord-occidental (DECat); a la resta del català continental campen navaixa, navaja, que són adaptacions del cast. navaja (Veny La importación)

patard, patarc 'grivieta, Symphodus rostratus' (<potard, derivat de pot 'llavi' + suf. augmentatiu -ard < germ. HARD): Roses, Cambrils (Huguet 167), Calella, l'Escala, Cadaqués, Arenys de Mar (Plaja i Güell 1956-58, ap. DECat; Veny Etimologia). Petarc és normatiu. Doc.: com a malnom, 1743 i 1750 (Amigó, Materials 44).

DCVB).

radolar (< rodolar < ROTULARE): Mallorca, Eivissa (Forteza $n, \mathrm{n}, f$;

raturar (<roturar): el Pinós (ALDC).

saldar (< soldar): Mallorca (Forteza II).

saldat (< soldat 'militar'): vulgar a Mallorca; Sineu (ALDC). Riera).

top. (Vila)tarrada (Pla de Bages) (< Vilatorrada): Moià ( Carles

top. Barball 'vall que va de la serra de les Puntes de Gandesa fins al riu Matarranya' (<vora vall): Vilalba dels Arcs (Monner n. 1609).

trabar (< trobar, per "tempo allegro" en la forma trebarien 'trobarien'): Moià (Carles Riera 27).

En els casos que segueixen la vocal tònica [a] que provoca l'assimilació no es troba en la síl-laba immediata:

batavant 'llambroix' (< botavant, compost de botar + avant): Campins, Llagostera, Palamós, Alp, Lledó, Begur (ALDC), Bagà, la Pobla de Lillet, Rupit (DCVB).

barifaci, banefaci 'beneitó' (< bonifaci < BONIFATIUS): Alp, Meranges, Cervelló (ALDC).

cagullada, cavullada, caüllada (< cogullada, derivat de cogulla $<$ CUCULLA): Marçà, Saidí; valencià central i meridional (ALDC).

manicaco 'home molt lleig' (< cast. monicaco): Rosselló. Doc.: Saisset, Catalanades, ap. Gallart 249.

prapaganda (<propaganda): vulgar a Mallorca.

prapassar (< propassar < cast. propasar): Mallorca (Felanitx [Forteza 59, n. a ]), Menorca (parpassar) (DCVB).

ratxegar 'vomitar' (< rotxegar): Andorra (Manel Riera). 
safalcar 'estrènyer la manada de cereals' ( $<$ sofalcar < SUBFALCARE, DCVB): mallorquí.

salaiat (< assoleiat): Maçanet de Cabrenys (ALDC).

tarruana 'alosa' (< torrodana, torredana < “TURRITANA [DCVB]): Sanet (DCVB).

top. (Casa) Bardegassa (< Bordegassa, derivat de bord): Sitges. Doc.: a. 1861 (Vinyet Panyella 108).

top. Bagunyà (< Bogunyà < voconianu [Onomasticon]): poblacions del català oriental (DCVB; Onomasticon).

top. Bargunyà (< Borgunyà < Bogunyà < VOCONIANU [Onomasticon] ]): poblacions del català oriental

top. Salaçar 'carrer d'Ulldemolins' (< solaçar, derivat de solaç): Ulldemolins (R. Pere - R. Amigó, Toponímia 66 i 349-50).

b) Interior

aclacar-se 'ajupir-se' (< aclocar-se, derivat de cloca (DECat, s.v. cloca, 241 a; [vegeu l'aragonès aclocarse, acoclarse ], però el DCVB parteix de l'onomatopeia clac, cosa que sembla menys probable): Llofriu, Tortosa (DCVB).

ant.volantat, volentat (< voluntat o volontat): probable influència de volent (DCVB), com sembla que ho abona la forma valenciana del Tirant. Doc.: R. Llull, Tirant, doc. a. 1380, Sant Graal (DCVB). Vegeu valuntat.

bavarada (< bavorada [encara a Eivissa], derivat de bavor VAPORE): Mallorca (DCVB). Normatiu.

cogaiada (< cogüiada): Moià (Carles Riera). Vegeu cagullada

encafurnat (< encofurnat): Pons, Massalcoreig (DCVB).

esbaldregar (< esboldregar, format sobre boldró): Mallorca (DCVB, Aguiló Dicc), Felanitx (ALDC). Postverbals: esbaldrec, esbaldregat, esbaldregada. Els quatre mots, normatius.

esvaletec (< esvoletec): Moià (Carles Riera). Postverbal d'un resvaletegar

bortalà (< bortolà < HORTOLANU): Barcelonès, Baix Empordà (DECat), mallorquí.

malfarjat (< malforjat, compost de mal i forja): Segarra, Priorat, Ribera d'Ebre, Maestrat (DCVB). Podria haver influît el sinònim malfargat.

ravalada (< revolada): Moià (Carles Riera), Lloret de ravalades 'amb pas insegur, vacil-lant' (Fàbregas-Rebollo).

salabrar (< salobrar, derivat de salobre): Mallorca (Llucmajor [ALDC]).

tafanari 'darreres, cul' (< antifonari < ANTIPHONARIUM). 
top. Bonesaires (< cast, Buenos Aires): Mallorca (Forteza $1, \mathrm{n} . f$ ). top. Mallapart 'Garrotxa' (< Mas Llopart < MANSU LEOPARDU) (Cardús 41).

verdalaga (< verdolaga < PORTULACA $\mathrm{x}$ verd): català oriental (DCVB), Bassegoda (ALDC)

$\mathrm{La}[\mathrm{u}]$ originària pot ser també objecte de centralització:

gasarapa (< gusarapa < probablement cast. gusarapa): Moià (Carles Riera 27); Font de can Gasarapa: Argentona (Richou 18).

Alguns dels mots anteriors poden explicar-se també per assimilació a la vocal central àtona $(a)$ o per dissimilació d'una altra vocal àtona velar $(b)$ :

(a)batavant, esbaldregar, esvaletec, prapaganda, prapassar, ratxegar, revalada, safalcar, salaiat, verdalaga, Barball (< Baraball), Bardagassa, Mallapart, Salaçar, Vilatarrada, gasarapa.

(b) cagullada, encafurnat, redolar, raturar, tarruana, Bagunyà.

\section{Casos de dissimilació:}

a) de la tònica tancada /ó/:

[o]...[ó] $\rightarrow$ [ə]...[ó]

a) Inicial

ant. i dial. palvora, pavora 'pólvora' (< polvora): mallorquí (DCVB; Alomar). Per a la pronúncia paroxítona, vegeu la rima polvora / tisora del Procés o disputa de viudes $i$ donzelles (DCVB).

ant. llaor (< lloor < llat. LAUDORE). Freqüent a l'Edat Mitjana.

ant. sejorn, sajorn (< sojorn < so + jorn < SUB + DIURNU). També sejornar i sejorniu (DCVB).

antrop. Chancosa (< Joncosa, Juncosa): valencià (Moll Els llinatges).

antrop. les Manyoses ( < feminització i pluralització del cast. Muñoz): Eivissa (Moreu-Rey 1981, 48). IOI).

atonyo 'tardor' (< cast. otoño): Cabra (Alt Camp) (Recasens, Estudi

babó 'en llenguatge infantil, dolç, llaminadura' (< bobó): Barberà del Vallès (informació de Lídia Pons).

bambolla (< bombolla < bolbolla); Mallorca, Plana de Vic, Alta Ribagorça, Matarranya, Conca de Tremp, Segrià, Noguera, Conca de Tremp, Priorat, Baix Ebre, Maestrat, Horta de València, Valls de Pego, marquesat de Dénia, comarca de Xixona, comarca d'Alcoi (DCVB i ALDC s.v. butllofa). Doc.: R, Llull, Micer Johan, J. Roig, F. Alegre. 
barromba 'esquella molt grossa' (< borromba): català central (DCVB; DECat; Riera 1993). Mot normatiu. Variant: barrumba. Origen onomatopeic. Vegeu barrombi $(2, \mathrm{c})$.

barrons (< borrons, derivat de borra): Cruilles (ALDC).

bató (< botó): Manacor (alterna amb botó, Puigròs 1998, 134), Pollença (terme nàutic) (ALDC). Vegeu batonar.

cabrombo 'cogombre' (< cobrombo): Xàbia (ALDC).

candort (< condor < cóndor): Moià (ALDC).

cató (fluix) (< cotó fluix): Moià (Carles Riera 28-29).

clafoll, clafolla (< clofoll, $-a)$ 'clova': valencià septentrional, nordoccidental meridional ; carfoll, es-, caoll 'grill de ceba' (Fraga, Cardós), carfolla 'embolcall de la castanya' (Andorra) [DCVB, DECat s.v. clova ], carfell 'clofoll de la ceba' (Cerdanya [Figuera 215). Doc.: clafolla (Busa-Nebrija, ap. DECat).

fagó (< fogó): Felanitx (ALDC), Santanyí (informació de C. Aguiló).

galfó 'golfo' (< golfó): Ribagorça (Alins, Senet, ALDC), Alt Pallars, Balears, Alguer (DCVB, ALDC, Veny Paralelismos, \& 67, DECat). Doc.: des del s. XIv. Wartburg, referint-se a l'occità gafóu, suggereix l'influx de gafa (FEW, IV, I93 a)

lladó, lledó 'fruit del lledoner; nom antic de l'arbre; topònim de l'Alt i Baix Empordà i del Matarranya' (< LOTONE [DECat]): nom general, articulat amb e en català occidental i amb neutra a l'oriental.

llagost (a) (<Hllogosta < LOCUSTA). General al costat de llangost(a), potser provinent de LONGUSTA. General i normatiu (DECat, Veny, Mots 121-122 i mapa núm. 6).

madorra (<modorra): Almenar (ALDC).

magró, macarró, mucarró (< mugró): Freixenet de Segarra, Begur (ALDC), Alt Empordà (Luna 290); en el segon cas, possible homonimització ulterior amb el nom de la pasta.

modaló (<modoló < MUTULONE): català oriental i sudest del nordoccidental (DCVB, DECat). Doc.: O. Pou (mudaló).

malló (< molló): Saidí (ALDC).

mandongo 'conjunt de budells; conjunt d'operacions que es fan, quan el porc és mort i obert, per a l'elaboració dels embotits' (< mondongo): Amposta, Granyena de les Garrigues (ALDC), Pallars (Coll).Vegeu mandonguilla. DECat).

marfondre ( $<$ morfondre $<\mathrm{fr}$. morfondre) : català oriental (DCVB,

palmons, palmós, espalmons, espaumons (< pulmons): català oriental, balear, Beneixama (ALDC).

parró (< porró, derivat de porro): Felanitx, Sineu, Sóller (ALDC), Santanyí (Aguiló).

pató 'petó' (< potó [encara rossellonès], potxỏ [Ribagorça, Pallars], 
derivat de pot 'llavi'). Català central. Normatiu. Doc. des del s. XVII (DECat).

raldor (< roldor < "RORETURIU): Peramola (ALDC), la Selva del Camp. Doc.: Lleuda de Cotlliure (s. XIII), Llibre del Mostassaf de Mallorca (s. XIV-XV) (DCVB); doc, a. $1584^{~ " c u l l e n ~ a v e l l a n e s ~ y ~ r a l d o ́ ~ " ~}$ (Albiol, Moreu, Toponímia 518) i a. 1700 (l'Albiol, in Anguera 123). Vegeu raudor.

ramor 'remor' (<RUMORE). Doc.: Graal; remor Sant Vicent Ferrer, Tirant, J. Roig. Remor és general i normatiu.

sacós (< socós < SUCCURSU): mallorquí, dins contextos com Mare de Déu del Secós, carrer del Secós ; Rosselló (sacors [Fouché, Phonétique 74]. Doc.: Crònica de Muntaner (secors), Crònica de Desclot (secós), Enquesta del Sant Graal (secós, sacós), doc. mallorquí de 1400 (DCVB).

saroll ( < soroll < *susurRuculu): Vandellòs, Pratdip (Recasens, Estudi Ior).

top. (Pujada del) Maló, del Moló : Vila-seca (Amigó, Toponímia de Vila-seca 99).

top. ant. (lo bac d'en) Satorre (< Satorre): l'Aleixar. Doc.: 1623: "lo bach den Sotorre"; 1640: "lo bosch den Satorra" (Manent 4r). La cronologia de la documentació sembla abonar el pas Sotorre > Satorre en aquest cas concret; en d'altres, el punt de partida pot ser l'aglutinació desa Torre.

Dels dos casos següents d'alternança no en coneixem l'etimologia:

top. Panoig, Ponoig 'muntanya de Polop de la Marina' (Llorca).

top. Margotx, Morgotx 'partida de la Marina' (Llorca).

\section{b) Interior}

carranyós (fer el -) 'fer el ploricó' (< carronyós, derivat de carronya < it, carogna): Valljunquera (ALDC).

estaló (< estoló < STOLONE) (DECat). Normatiu.

antrop. Gravalosa, Grabalosa, Gravalós, Grabalós (< grevolosa, derivat de grèvol < llat. vulgar ACRIFULUM) (Moll Els llinatges).

mesaró (< mesuró, diminutiu de mesura): Sant Privat d'en Bas (ALDC).

salamó (< salomó < SALOMON): estès per tot el domini, alternant amb salomó. Per a Salamó (Barcelona), vegeu Milà 4. Doc.: Homilies d'Organyà, Isabel de Villena (DCVB), Llibre d'Antiguitats de la Seu de València, ap. Martí Mestre 1994, 91; Pujades, Dietari, I, 126.

antrop. Santaló (< sant Odló < SANCTU + fràncic ODILONE, Onomasticon); també els top. Fontalona i ant. Alonem i Casalone. 
Amb la [u] tònica també pot haver-hi centralització de [o] (o de [u]): aixapluc (< aixopluc, postverbal d'aixoplugar-se): Cànoves (ALDC), Aiguafreda, Barberà del Vallès (enquesta personal)

ant, escur (< OBSCURU): Doc.: Llull, Muntaner, Metge, etc. I mots del seu camp derivatiu: escurir (Franja [ALDC]), escuritat.

antrop. Danús (< ${ }^{*}$ Donús < DONUCiUs < DOMNUCIUS): Mallorca, Menorca (DCVB, Moll 1982).

cafurna 'casa petita i mal endreçada'(< cofurna): Ponts (Noguera); cafúrmula 'catau, lloc fondo i encongit' (Lluçanès) (DCVB). Però, si fos derivat de CAvUS $X$ Furnus (DECat), aquest exemple, com el d'encafumat, no valdria.

caluix 'tronxo, ull tendre' (< "coluix < llat. CAUle osseu). Mot general i normatiu.

camuna 'classe d'avellana' (< comuna): Prades (Recasens, Estudi IOI).

caramull 'munt' (< corumull < CUMULARE $\mathrm{X}$ "COROLLIARE [DECat]): Balears i punts diversos del català occidental, on sembla que predomina la variant cor-(DCVB, DECat). Normatiu. Doc.: des del s. XIX. Derivat: acaramullar, també normatiu.

carnut (< cornut < CORNUTU): Bescaran (ALDC).

faburt (< fobur < fr. faubourg): Rosselló (Fouché, Phonétique 74; ALDC, Saisset, ap. Gallart).

fatut (< futut): vulgar a Mallorca.

jantures 'junteres (del jou)' (< juntures): Pollença, Montü̈ri, Ciutadella (ALDC).

magut, -uda (< mogut, -uda): vulgar a Mallorca; maguda 'es diu d'una cabra o ovella que va calenta' (Santanyí) (ALDC).

paruc (<poruc): català oriental, balear (ALDC, DCVB, Recasens, Estudi Ior).

ramput (<romput): vulgar a Mallorca; Felanitx (ALDC).

rabust (< robust < ROBUSTUS): Balears, Conca de Tremp (DCVB). Doc.: Cançoner dels Masdovelles, En català occidental, trobem la variant rebust, que ja apareix en el Curial /DCVB).

sacutre 'sacsejar' (< sUCCUTERE): Rosselló (Fouché Phonétique; Botet). Es documenta secutida ja al 1428 (DECat). Vegeu sacudir.

sapluig (< sopluig): Tossa de Mar (ALDC).

top. Banús 'masos del català central i Balears' (< Bonuç, derivat de bo). Trobem un Benucii el 1063 al Cartulari de Sant Cugat.

top. Besalú (<Besoldú < BISUldunu) (Onomasticon).

top. Farrúbio 'topònim de Roquetes' (< FONTE RUBEU) (Coromines, Tópica 42, n. 8).

valgut (<volgut): Felanitx (ALDC).

En els casos que segueixen, la [o] tònica no es troba a la síl-laba 
immediata (botaló) sinó a la següent; aleshores la presència d'una a àtona veína podria ajudar a l' assimilació de la /o/ àtona a aquesta vocal central:

a la millor (< a lo millor): Terra Alta, català central. Doc. Fabra 1934 (ap. Miravitlles 97 i 114 ).

ant. esbramadora, esbremadora, bramadora (< esbromadora, derivat d'esbromar). Doc: segles XIV i XV.

ant, galaró (< goleró). Doc.: Torra (s. XVII) ("Bullidor d'aygua. Vorago, barathum").

ant. gamfaró, gamfanó 'estendard de guerra' (< gomfanó < germ. GUNDFANO): Barcelona, Empordà (DCVB). Doc.: a les nombroses citacions del DCVB, afegiu Pujades, I, 131; 145, a. I60I ("atabals, ganfanons); II, 99, a. 1609 ("bandera y ganfanons).

antrop. Camallonga (< Comallonga) (Moll, Els llinatges 271).

bataló (< botaló): Pollença (LMP), Sant Feliu de Guíxols, Manacor (DCVB).

comanió (< comunió): Moià (Carles Riera).

macador (< mocador): Arbeca (els vells), Rossell, Móra la Nova, l'Ametlla de Mar, Pego, Tàrbena, València (ALDC); en alguns d'aquests punts, alternant amb mocaar, mocador) (ALDC).

rataboc (<rotaboc): Santanyí (Mallorca) (informació de C. Aguiló). sabatuda, sambatuda 'sotragada, cop fort' (< sobatuda, derivat de sobatre < "SUB-BATTUERE): Mallorca (DCVB).

tavalló (< tovalló): Amposta, Lleida, Ulldecona. Mas de Barberans (ALDC), Ós de Balaguer (Fortuny). Vegeu tavallola.

trançador 'verduc' (< tronçador < arag. tronzador): Sopeira, les Paüls (ALDC), No enregistrat als diccionaris catalans

\section{b) de la tònica oberta [0]}

ant. prapòsit (< propòsit < PROPOSITUM). Doc.: R. Llull; Tirant (prepòsit) (DCVB).

antrop. Palòni(a) (< Apolònia < APOLLONIA): Mallorca, Empordà (DCVB), Prades (Amigó, Noms de lloc 2ni).

barnois, bornois 'flotadors del sardinal': Maresme. Doc. Salvador 172I, ap. Lleonart-Camarasa 1987, 53).

batllofa (< butllofa o *botllofa): Pallars Jussà, Pallars Sobirà, Noguera, Segarra, Matarranya, Avià, Girona, Tossa de Mar, Palamós (ALDC, DCVB).

calbot 'cop al cap' (< “colbot < colpot [Colón]; però Coromines parteix de colpat, a través del mossàrab [DECat s.v. calb], hipòtesi difícil d'acceptar): valencià; Barcelona. Normatiu. 
calònia 'aigua de colònia' (< colònia < COLONIA). Vulgar mallorquí. Vegeu top. Calònia.

calostre, calostro (< colostre, encara a Vilar de Canes i Vistabella [Maestrat, DCVB] < llat. Colostrum). General i normatiu (calostre).

carriol (<corriol): Pallars (Coll).

ceballot (< sebollot. format sobre cebolla < CEPULL $\Lambda$ ): català oriental i nord-occidental (DECat). Podria haver influit ceba. ceba.

ceballol 'cop' (< cebollol): Mallorca (DCVB). Podria haver influit (Gimeno 375).

manjoia 'monjoia, mona de Pasqua' (< monjoia): Ulldecona (ALDC).

parenòstic (<pronòstic) : Mallorca. L'etimologia popular (homonimització formal) passa el mot de parnòstic, parenòstic a [para nóstik]. pariol 'poliol' (<poriol < poliol): Palma (ALDC). (ALDC).

samoll, samoi 'classe de cep' (< somoll): Vimbodí, Móra la Nova

taronja (< toronja < àrab turunga). General i normatiu.

top. (Cal) Basoms, Bosoms (<Bons Homs): Balsareny (Carreté).

top. (Les) Sarroges 'partida de terra d'Albarca' (<les Sorts Roges). Doc.: Sort(s) Roges (a. 1398, 1448, 1500); Sarroges (a. 1589, 1625, 1711) (Llopis).

top. Calonge (Baix Empordà i Mallorca) $(<$ Colonge $<$ COLONICU, Onomasticon). Pel que fa al topònim de Mallorca, estic d'acord amb la proposta de Moll (ap. Mascaró Pasarius) que el considera una exportació del nom de lloc empordanès i discrepo de Coromines que el fa derivar de Cala Llonga.

top. Llacnou (Albaida) (< Lloc nou) (Informació d'A. Ferrando).

top. Magòria 'riera del Barcelonès' (< Mogòria): Moran, Notes $112-113)$. 33).

top. Parroig, Porroig (<port roig): Vila-seca (Amigó, Toponimia

top. Partbou 'poble de l'Empordà' (< Portbou).

top. Plans de (i Peça de) Bamiola (<* BURNIOLus ?). Alterna amb Burniola.

top. Sa Calobra (< Colobra < COLUBRA [Onomasticon])

top. Sa Calòni(a) (agregat del municipi de ses Salines [Mallorca]) $(<$ Sa Colònia). Vegeu calònia.

top. Tarroja 'poble de Segarra', les Tarroges 'agregat de Bellvís' (< Tor [re] roja); pronúncia alternant a Torroja 'poble del Priorat', mentre que els anteriors són formes normatives. Tarroja també és antropônim, documentat al Maresme des del 1580. 
Casos en què la vocal $o$ oberta tònica no es troba en la sílllaba immediata sinó en la següent a aquesta:

(figa de) bardissot (< bordissot): Cànoves, Cervelló (ALDC); pot haver-se creuat amb bardissa (homonimització formal).

ant. malenpoli, manimpólit 'xerrameca, pretensions inacceptables' (<monopoli) (DCVB).

antrop. Mariscot (< Moriscot, derivat pejoratiu de morisc) (Moll Els linatges).

antrop. Sererols (< top. Solerols, derivat de Soler): Bages, Moianès (Moreu-Rey 199I, 203); no seria una variant de Cirerols, com proposava Moll (Els llinatges 23I).

barinot, borinot: Sant Pere de Ribes (ALDC).

calpissot 'clatellada' (derivat de colp, vegeu calbot): Castelló (DCVB).

flaricol 'coliflor' (< floricol): Conca de Barberà, Alt Camp (Plaza 263).

masqueroles 'classe de pera' (< mosqueroles): Margalef de Montsant (ALDC).

pasterol, pastirol, pasturol (< posterol < POSTERIORE [DECat]): Tarragona, Mallorca (DCVB). Normatiu. Doc.: Fenollar, O. Pou, Dię̧ (DCVB).

patracol (< protocol). General, normatiu. Potracòl a Aguiló, Rondaya de rondayes, 1817,7 .

rabiol 'pasta dolça' (< robiol): Manacor (Puigròs 134). Encara que pogués derivar de l'it. raviolo (Veny, Mots 53), la forma general des del s. XVI és rabiol o rubiol, mentre que rabiol és simplement opcional.

ramarol 'persona bellugadissa, que xerra molt i animadament' (< remorol): Mallorca (Forteza In, n. f). Doc.: Roca, Rondalla de rondalles.

raquerol (<roquerol): Arbeca (ALDC); també requerol.

tarterol 'turmell' (< torterol): Almenar (ALDC).

tavallola, tavaiola (< tovallola): Moià, Baix Ebre, Segrià, valencià central i meridional, mallorquí, eivissenc (ALDC, Carles Riera 27, Fortuny).

top. (La) Barroca (aldea de Sant Aniol [Olot]) (< Sabarroca < Sobrerroca). Ulterior substitució del fals article sa per la (Coromines, Tópica 258, n. 8 i Onomasticon, s.v.).

trampitxol 'burot' (<trompitxol): Amposta (ALDC).

La [u] també pot ser afectada pel canvi:

basaroca (< busaroca): Moià (Carles Riera), Ripoll, Bigues (DCVB). 
c) de l'àtona [o]:
$[\mathrm{o}] \ldots[\mathrm{o}](\mathrm{o}[\mathrm{u}] \ldots[\mathrm{o}]) \rightarrow[\partial] \ldots[\mathrm{o}]$

(sèver) sacotrí (< sucotrí) : Empordà, Vendrell (DCVB); all ensacotrí 'all silvestre': Rosselló (Fouché, Phonétique 74).

agramollar-se (< agrumollar-se, derivat de grumoll < "GRUMUCULUM): Camp de Tarragona (Recasens, Estudi Ior).

aixaplugar-se (< aixoplugar-se < soplujar-se x esplugar-se): Pinós (Solsonès) (DCVB). Vegeu dixapluc.

ant. i dial. sacudir, (<"socodir < succuTERE): Ribagorça, Eivissa (DCVB; Veny Els parlars); sacutir (Rosselló [DECat, Botet]), vegeu sacutre.

ant. sadomia (< sodomia): Mallorca. Doc:: a. 1498 (Rosselló, L'bomosexualitat a Mallorca, $8 \mathrm{i} 10$ ).

avalotar, esvalotar (< avolotar, pres del llat. vOLUTARE [DECat s.v. esvalotar]). General i normatiu. Doc.: avalotar, des del s. XIV; esvalotar, des del s. XIX.

barronar (< borronar, derivat de borró, format sobre borra < llatí tardà BURRA): Cruilles; Maçanet de Cabrenys (barromar), Begur (barronejar) (ALDC). Vegeu barró (2 a).

barrombí, barrombill (< borrombi): Banyoles (DCVB). Mot onomatopeic. Vegeu barromba (2 a).

batonar (< botonar, derivat de botó): Castellfollit de Riubregós (ALDC). Vegeu bató.

batua (< voto a): Catalunya, Mallorca (DCVB).

cantornat, -ada (< contornat): Elx (Segura 123).

casconilla, casconia (< cosconilla, cosconia < probable metàtesi de coscollina): Vallès, Penedès, Empordà, Menorca, Moià (DCVB, Recasens Estudi, Carles Riera 28). Doc:: "Casconia. Hieracium taraxacium" (Ramis 47); "a cercar llençons i casconies " (Benejam 26).

cassonat 'corcat' ( < cossonat, derivat de cossó < fr. cosson [DECat, s.v. $c u c$ ]): Estagell (ALDC).

eixamorar (< eixumorar < EXHUMORARE): Maestrat, Tortosa; català oriental (DCVB).

entajolar-se (< enrojolar-se < "enrojorar, format sobre rojor [DECat]): Ripoll, Empordà, Barcelona (DCVB).

enfarfegar (< enfrafegar < "enfrofogar [cat. occidental enforfogar ], format amb enfre i $*$ ofogar): català oriental.

(en)terbolar $("<$ (en)torbolar < "TURBULARE). Doc.: R. Liull, Albert el Gran, doc. a. 1340, Averçó (DECat).

escatolit (< escotorit): Tossa, Centelles (DCVB).

estapolaniy 'tap de bóta', 'bastonet amb una munyeca d'estopa que s'introdueix en la boca de les cavalleries amb finalitat curativa' 
(< "estopolany, derivat d'estopa): Plana de Vic (DCVB). Normatiu. Doc:: O. Pou.

estramanció (< Extremunció): Cervelló (ALDC).

flacolera 'herba colera' (< flor colera < occità flor caulièra): Els Hostalets (Rosselló) (ALDC).

galandrino 'bua' (< cast. golondrino): tortosí meridional (Gimeno). garjoliu 'papada' (< gorjoliu, derivat de gorja): Llagostera (ALDC). Vegeu garjoles 'barbelleres'.

granxolar (< gronxolar, derivat de gronxar): Rosselló (Llançà,, Prats de Molló, Perpinyà [ALDC], Perpinyà, Oleta, Illa de Tec [DCVB]). Doc: Grandó 1943, Botet.

mal [mal] (< molt, dins el context si molt convé): català central (DECat, s.v. altre).

(mal)amoregat 'de mal humor' (<malhumoregat, compost de mal i un derivat d'bumor ; creuament amb malamorós ?): Creixell (enquesta personal).

mandonguilla (<mondonguilla, creuament del cast. albondiguilla amb mondongo): DCVB. Normatiu. Cf. mandongo.

margonar (< amorgonar, amurgonar): Ciutadella (ALDC).

marmular (< murmurar): València, Mallorca, Menorca (DCVB), Conca de Barberà (Plaza 1996).

palmonia (< pulmonia): Barberà del Vallès (informació de Lídia Pons), Moià (Carles Riera), Esterri d’Àneu, Begur (aplicat als cavalls) (ALDC). Vegeu palmons.

parçoner ( $<$ porçoner < PORTIONARIU). General i normatiu.

patracol, pratacol (< protocol): català oriental, mallorquí (DCVB). Patracol és normatiu. Cf. més amunt.

pravocar, parvocar 'tenir nàusees' (< provocar): català central, mallorquí, menorquí (ALDC). En alguns punts nord-occidentals [perßoka], per homonimització semàntica.

samontà 'raïguer' (< somontà < SUB MONTANU): Sant Boi de Llobregat (ALDC). Per a la 0 originària, compareu amb l'aragonès Somontano.

top. Campostela (< Compostela): Mequinensa "la carretera de Santiago é la guia d'anà a Campostela " (ALDC).

top. la Donzell 'poble d'Urgell i llogaret de la Baronia de Rialb' ( $<$ lo Donzell) (Coromines 1976, 130).

top. la Gornal 'poble del Baix Penedès' $(<$ lo Gornal) (Coromines, Entre dos 130).

top. La Molso(r) 'engorjat del terme de Queralbs' (< lo Molso( $r)$ ) (Coromines, Entre dos 130).

top. la Porro $(r)$, clot de 'vall de Tregurà' (probablement < lo Porror $<$ (SALTUS) PORRORUM [Coromines, Entre dos 131).

top. i antrop. Tarruella ( $<$ Torrosella < TURRICELLA): antrop, català 
central (DCVB); top. el Puig de la Tarruella, la Tarruella de Dalt (Vilallonga de Ter, Amigó 1979, 1617). A la documentació antiga de Reus, alternen Torrosella /Terrosella / Torroella / Terroella (segles xIv a XVI) (Amigó, Materials 593).

trantollar (< trontollar): Tortosa, Maestrat (DCVB; informació d'Àngel Massip), Doc.: atrantollar, trantollar 'marejar-se, torbar-se el cap per l'excés de moviment' (Ros 1764); atrantollarse "macarse" (Lamarca).

valuntat (<voluntat o volontat): Manlleu (Moran, Comentari 22), Mallorca (Forteza $\mathrm{n}, \mathrm{n} . f)$, antic i vulgar català oriental i menorquí (DCVB, DECat). Podria ser una metàtesi de volantat (vegeu el mot), però no és probable. Vegeu valuntari.

valuntari (<voluntari): Maçanet de Cabrenys (ALDC). Vegeu valuntat.

vardolaga, verdolaga (< bordolaga < PORTULACA). Sembla clara l'homonimització amb verd. General.

xacolata (<xocolata < cast. chocolate): Cat. oriental. Doc.: Reixac v. 1748, II, CXI).

xafagor (< xafogor): Tossa de Mar, Llançà (ALDC).

d) per contacte o diferenciació:

$[\mathrm{ow}] \rightarrow[\mathrm{ow}]$ o [aw]

antrop. Aumadell ( $<$ *oumadell $<$ olmadell).

antrop. Aumet (< oumet < olmet): llinatge de terres gironines (DCVB; Moll Els llinatges).

antrop. Raureda (< roureda). Per a aquest nom i per a Raureda cal tenir en compte la possibilitat d'una derivació directa de la variant antiga i dialectal reure.

antrop. Rauret (<Rouret, derivat de roure + sufix -et) (Moll, Els llinatges 240).

antrop. Rauric ( $<$ Rouric $<$ germ. HRODRICH) (Moll, Els llinatges IIg). aufrany (< *oufrany < olfrany) (DECat s.v. bora). Normatiu.

aumisser 'om' ("oumisser < olmisser): Peramola (ALDC).

caüllà 'cogullada' (< coüllà < cogullada): vegeu cagullada.

caurà (< courà, futur de coure): Barcelona (Milà 4), Moià (Carles Riera 26).

cautivar (< ${ }^{*}$ contivar < cultivar): el Pinós (ALDC).

claurà (< clourà, futur de cloure): Barcelona (Milà 4; Fabra 12, n. 2) esvauvar (< esvoüvar < esvolvar): Mallorca (alternant amb esvouvar) (DCVB).

maurà (< mourà, futur de moure): català oriental (Milà 4; Fabra 12, n. 2; Fouché, Pbonétique 74). 
mantó (<moutó < moltó): Freixenet de Segarra (ALDC).

plaurà (<plourà, futur de ploure): Barcelona (Milà 4; Fabra 12, n. 2), Rosselló (Fouché, Pbonétique 74), Moià (Carles Riera 26), Ciutadella (ALDC).

raudor (< roudor < roldor): Baix Penedès, Alt Camp, Alfarràs, Montsonís, València (DCVB). Vegeu raldor.

top. Raureda (< roureda, col-lectiu de roure): Vilallonga de Ter (El camí de la Raureda) (Amigó 1979, 207).

top. i antrop. Raurell ( $<$ Rourell $<$ der. de roure + suf. - ell $)$ : Moià (Carles Riera 26; Moll, Els llinatges 240).

En posició de hiat:

la un 'I'un' (< lo un): Rosselló, Camp de Tarragona, Baix Aragó, català central (Milà 4; Recasens Estudi). No crec acceptable la interpretació que per a idèntic canvi de l'occità proposaven NouletChabaneau (1888), és a dir, per analogia amb cada un, cada una.

Existeix la possibilitat del pas invers [aw] > [ow]: courà 'caurà' (Alaró, ALDC).

\section{Altres casos}

ant. fanèvol 'màquina de guerra' ( $<$ fonèvol < Fundibulu). Doc.: Jaume I (DCVB). Hi podria haver ajudat l'atracció homonímica de fendre (DECat, DCVB); el pas fon vol > fonòvol > fenòvol (per dissimilació) > fenèvol, per compromis entre fenòvol i fonèvol, que proposa Coromines, no sembla necessari.

antrop. (Serra)melera (< Serramolera) (Moll Els llinatges).

balangera (< bolangera): Peramola (ALDC). Per a balongera, vegeu més avall.

banito 'bonítol' (< probablement cast. bonito): Tossa de Mar, Badalona (LMP).

catxel "escopinya de gallet, Crestoderma edule" (< "conxel $<\mathrm{CON}$ CHYLIUM 'caragol de mar; petxina', Veny Catxel): delta de l'Ebre. Normatiu (DIEC).

clapissa 'bolet blanquinós que es cria a la soca dels clops tallats' (< derivat de clop < PLOPPU, + suf, -issa): Bolvir (DCVB). Es evident que aquesta accepció hauria de figurar com una entrada diferent a la de clapissa 'paratge de roques'.

clatell (< clotell, encara balear; derivat de clot + suf. -ell): general i normatiu.

claveguera ( $<$ clovaguera < CLOACARIA). General i normatiu,

esparti (< esporti, derivat d'esporta): Artana, Llucena (DCVB), espalti (Castellfollit de Rubregós). Possible homonimització amb espart. 
gatim 'porció de raïm, bagot' (< gotim): Camp de Tarragona; Arbeca, Mas de Barberans, Vimbodí (DCVB, ALDC). Doc.: Girauld 1587, ap. Veny La interferència (mot sense documentació al DCVB i al DECat)

gatimell (derivat de gatim): Rosselló (Grandó, Botet).

Ilambric 'cuc' (<llombric < LUMBRICU; però Jud, seguit per Coromines, postula una probable variant llatinovulgar ${ }^{*}$ LIMBRICU a partir de parlars dialectals dels Alps i d'Itàlia septentrional [DECat]): català nord-occidental (Bonansa, Cardós, Tremp, Balaguer, Pla d'Urgell [DCVB]). Normatiu.

llambrigol 'llambric, cuc' (< LUMBRICULU): valencià (DCVB).

llambrigol, llambrigo 'melic' (< llombrígol < ILLU UMBILICULU): Sant Privat d'en Bas, Bassegoda (ALDC), Darnius (DCVB), Rosselló (Grandó, Botet).

palpis (< polpis, derivat de polpa + suf. $-i$ s < -ICEU): General i normatiu, com polpís. No es pot descartar una "influència analògica de palpar," com insinua el DCVB.

rataliu 'ratolí' (< ratoliu): Queralbs (ALDC).

$s a$, variant de l'article definit es (dins contextos com amb so mànec) (< so < IPSU): "en la pronúncia molt relaxada de la pagesia de Mallorca” (DCVB). Potser això explicaria la variant de plural masculí, davant vocal, ses 'els' del salat continental (ses arbres) (cf. Veny Els parlars, 12a ed., 37).

safregit (< sofregit): Almenar (ALDC).

salsera 'alfabieta per a guardar-ho coses en conserva' (< solsera, derivat de sols 'condiment'): Mallorca, Menorca (DCVB). Possible atracció homonímica de salsera 'vas per a servir la salsa a taula' o simplement de salsa.

san endret, $a-(<a$ son endret): Mallorca.

tafaner (< "tofener, derivat de tòfena < TUFERA). La documentació de DECat és estrictament catalanocentral. Mot normatiu, amb els seus derivat tafaneria, tafanejar:

tremalitja 'cuc vermell de la platja' (< tremolitja): Menorca (DCVB).

top. (Cala) Marisca / (Cala) Morisca (derivat de moro + suf. -isca): Vila-seca (Amigó, Toponimia de Vila-seca 36).

top. (Puig)palter (< (Puig)polter, derivat de Pultes 'farinetes; fangueig, paratge llotós, humit' (Onomasticon, VI, 300-30r i DECat, S.v. paltada).

top. Flamisell 'riu del Pallars. afluent del Noguera Pallaresa' (< *Flumicellu [DCVB] o, com vol Coromines, <Flumencellu [DECat]) 


\section{B. INICIAL ABSOLUTA}

\section{1. assimilació a la tònica central [a]:}

abassegar (< abcegar < OBCAECARE) (DCVB, DECat, s.v. cec).

abcegar (ant.), encegar (< obcegar < OBCAECARE). Encegar, força estès, pot haver sofert substitució de prefix.

acubar 'sufocar' (< * ocubar < OCCUPARE [DCVB, però el DECat prefereix derivar-lo de cup): balear.

acupar (< ocupar): Moià (Carles Riera 28-29). Vegeu desacupar.

(des)acupar 'infantar, parir' (< desocupar): català central i occidental (ALDC, enregistrat a 48 localitats).

aliaigo (< oliaigua): Alaior (Menorca) (DCVB).

alivar (< olivar, derivat d'oliva + el sufix col-lectiu -ar): Llofriu (DCVB).

alivarda (< olivarda, derivat d'oliva + el sufix pejoratiu -ard (Llofriu) (DCVB).

alrada 'bravada, olor forta' (< olorada): Tremp, Senterada (DCVB, DECat)

andulat (< ondulat): Almenar (ALDC)..

ant. aldà 'vell' (< oldà < OLITANU, però Coromines prefereix < gòtic "ALDA, ALDAN 'vell' [DECat]): sentit als Llombards (C. Aguiló). ant. i dial. adular (< udolar < ULULARE). Doc, adulaments 'udolaments' (Sèneca, Tragèdies).

antrop. Alvan < Olvan (DECat s.v. hora)

antrop. Arlandis (< it, Orlandi): València. Doc.: Ontinyent a. 1867, SOBI, 26, 1986, 59 .

aturar (< llati vulgar "ATTURARE < OBTURARE) (DECat). General i normatiu.

axigenat, -ada (< oxigenat, en el context aigua oxigenada, per fonosintaxi): Moià (Carles Riera 28-29).

haspital (apel-latiu, topònim) (< hospital < HOSPITALE): Moià (Carles Riera 27), Reus (Amigó Materials), Gandesa (Monner 1683), Almenar (ALDC), l'Aleixar (renom) (83). Doc.: Spital (Amigó Materials, a. 1397), Espital (Font 152; Torra 286). Vegeu Haspitalet (B, 3).

top. (Ca) I'Alegàrio (< Olegàrio): Solivella (Moreu-Rey, Antroponimia 184). 


\section{Dissimilació}

a) de la tònica tancada [ó] (eventualment [ú]):

[o]... [ó] $\rightarrow$ [ə]...[ó]:

actubre (< octubre); Castellfollit de Riubregós (ALDC).

alor (< olor): mallorquí vulgar (Forteza II, n. $f$ ). Doc.: Vigilant despertador 263).

ant. apilacions (<opilacions). Doc.: Arnau de Vilanova.

ant. i dial, angüent (< ungüent): Moià (Carles Riera 28-29). Doc.: R. Llull, B, Metge (DCVB), Sant Vicent Ferrer, Jacme d'Agramont.

antrop. Alorda (< Olorda < preromà OLÓRBITE).

argull (< orgull $<$ fràncic URGOLI): viu opcionalment aquí $\mathrm{i}$ allà (DCVB). Doc.: R. Llull, Jaume I, Muntaner, Agustí (però ergull o derivats en $e$-en obres occidentals [Homilies d'Organyà, A. March]). avolles, avoies 'ovelles' (< ovuculas): Begur, Palamós, Llagostera (ALDC)

top. Alaró (< Oloron < ILURONE ?) (DCVB, Onomasticon).

ant. escur (< OBSCURU). Doc.: Llull, Muntaner, Metge, etc. I mots del seu camp derivatiu: escurir (Franja [ALDC]), escuritat.

b) de la tònica oberta [0]:

alicorn (< alicom < aricorn < unicom [DECat, s.v. corn). Mallorquí. Doc:: O. Pou.

altra bara, a - 'a deshores, a una hora molt tarda' (< a oltra bora, der. d'ULTRA [DEC s.v. hora i ultra).

armolls, ant. almolls, aumolls (< llat. HOLUS MOLLE 'verdura molla'). Doc.: Arnau de Vilanova, Macer (DECat).

\section{c) de l'àtona $[0]$}

afogar (< OFFOCARE) (DCVB).

adular (< udolat < ULULARE): Mallorca, Menorca i punts del País Valencià (DCVB, DECat). Doc.: Eximplis e miracles, Tirant, Sor Isabel de Villena.

top. (els) Alumins (< Olomirs, plural d'Olomir, variant d'Olomar) (DCVB).

ant. hamologar (< homologar). Doc.: doc. a. 1391, a. 1543 (DCVB, s.v. amologar).

asurer (<usurer): Mosset, Santa Eulàlia de Riuprimer, Ciutadella (ALDC). 
onom. (Sant) Hanorat (< Honorat): català oriental (Fouché, Phonétique 74), mallorquí. Doc.: a. 1393 (Fouché, Phonétique 74); "Anorat Clar, esparter" a. 1709, ap. Bartomeu Font V, 39).

\section{Altres casos}

aliva (< oliva) i alivera (< olivera): Begur (ALDC), Palamós, Llofriu (DCVB);

almatella, almutella (< olmatella, derivat d'olm).

almudella (<olmadella, derivat d'olm): la Pobla de Roda (ALDC). amplir (< omplir): Mas de Barberans; amplert Agramunt, Vimbodí (ALDC). Vegeu top. Amplidor.

ansi 'part corba del jou' (< UNCINOS 'ganxos, rames ganxudes'). General i normatiu.

angüent (< ungüent < UNGUENTUM): variant força estesa en el domini (DCVB), Moià (Carles Riera); "normal en el dialecte central, com sigui que fins i tot es pot sentir en boca de la gent culta" (DECat s.v. untar). Doc.: R. Llull, Metge, Tresor de pobres, Eximplis e miracles, Canals, Sant Vicent Ferrer. Coromines atribueix la variant a dissimilació entre elements velars $u n-\mathrm{i} g w$-.

ant, alciure 'matar' (< olciure, "olcidre < ociure) (DECat s.v. occir). antrop. Alibé, Alibés (< Oliver, Olivers) (Moll Els llinatges).

antrop. Almatell, Almató (<Olmatell, Olmató) (Moll Els llinatges), antrop. Ardeig < Ordeig < germ ORDIIG [Moll Els llinatges]): Barcelona, Terrassa.

antrop. Arpi $(<$ Orpí $<$ AURIPINUS [Moll Els llinatges]): Barcelona, Girona.

antrop. Estelric (< top. Hostalric). Podria haver influit una homonimització amb estel.

araneta 'oreneta' (< eroneta, d'un primitiu *erone $(n)$ amb diminutiu -eta, o d'una dissimilació d'oroneta [DECat]): Empordà, Gironès, Garrotxa). Doc.: M. Agusti, Baldiri Reixach (Veny "Dialectologia"). Per metàtesi i afèresi s'ha format nereta.

arguenells (* ORGANELlos, diminutiu d'ORGANA 'eines, instruments, ormeigs'): Banyoles, Sant Felie de Pallarols; Mallorca, Menorca (DCVB). Normatiu.

top. (Cova de) l'Hamdedeu (< Homdedéu, cognom): Cabacers (Biete, núm. 107, 249. 542, A 73, A 227). Doc:: Homdedéu a. 1553.

top. (riera de l') Amplidor (< omplidor): Aleixar. Doc.: a. 1656 (Manent).

top. (l)'Haspitalet < l'Hospitalet): Moià (Riera 1993, 27), Reus (Amigó Materials). Doc: "de la sglésia del Haspitalet" (a. 1585, ap. Madurell Hosp. 76). 
top. (los) Haspicis (< Hospicis): partida d'Arbolí (Prats 72).

top. Altés 'topònim de l'Alt Urgell'(< basc oTE-TSU 'esbarzerar' [Onomasticon ]).

\section{POSTTONIICA}

ant. antifana (< antífona < ANTIPHONA): Rosselló batre l'antifa 'córrer la gandaina', Doc:: R. Llull, Vides de sants rosselloneses (DCVB). Vegeu tafanari.

antrop. Càneves (< top. Cànoves < llatí tardà CANABA 'tenda, celler, taverna' [Onomasticon ]): Mallorca (DCVB].

filòsap (< PHILOSOPHUS): Eivissa (DCVB).

sàssala (< sàssola): Mallorca, alternant amb sàssola (DCVB).

tòrtara (< tórtora < TURTURE): Mallorca, Menorca (DCVB).

vànava (< vànova, aquesta és la forma tradicional, clàssica, tot $\mathrm{i}$ que l'etimologia sembla que, segons Coromines, seria GALNAPE): Mallorca, Menorca; Urgell (DCVB).

vulg. mettàfara 'enganalla, adulteració' ( metäfora < METAPHORA): Mallorca, Menorca (DCVB); mettafa (Migjorn Gran [Griera Tresor])

vulg. pàrraco (< cast. pàmoco): Barcelona (Milà 4).

vulg. telèfano (< cast. teléfono): català central.

vulg. velòdramo (< cast. velódromo): Reus (Amigó, Materials 606). vulg. braixala (< brúixola): L'Escala (LMP).

\section{PRETÓNICA INTERNA}

abalir 'destruir' (<abolir < ABOLERE): Empordà, Garrotxa (DCVB). boga-ravell 'Pagellus bogaraveo' ( $<$ boga-rovell $<$ BOCA RUBELLU [LEI]). General i normatiu. Podria ser un occitanisme (<bogaravel).

ant. conamina 'coromina' (< conomina < CONDOMINA). Doc. del s. VIII al s. XV, alternant amb conomina (DCVB, DECat).

cumanera 'jàssera, biga comunera' (< comunera): Porté (ALDC).

eixafagor, xafagor (< eixafogor, derivat de EXOFFOCARE): català nord-occidental i central (ALDC, enregistrat a 50 punts).

fredaluc, -uga 'fredolic; 'classe de bolet'; $f$. 'juia, fraret (ocell)' (< fredoluc, format sobre fredor ofredura): Rosselló, Cerdanya, Ripollès, Gironès, Empordà, Plana deVic (DCVB, DECat), Veny L'ètim). Normatiu (fredeluc, fredeluga). 


\section{Casos de metàtesi}

Són imputables a metàtesi:

sacorrar (< socarrar < basc su 'foc' i karra 'flama'): Mallorca, Menorca (DCVB)

sacorrell 'Launae cervicornis' < socarrell, vegeu sacorrar)

mirabolà (< myrobalanum). Normatiu. Recollit mirabolan a Linyola (ALDC). Sens dubte ha influit en el canvi l'homonimització amb mira, del verb mirar.

mujardom (<majordom): Banyoles (ALDC).

ramugar 'remugar'(< "rumegar < RUMICARE). General.

ballugar 'bellugar' (< bullegar < ‘BULLICARE). General, tret d'una part del valencià.

museró (< mesuró, derivat de mesura): Agullana, Besalú (DCVB).

agemolir-se (< ajumelir-se < ajupir-se x humelir-se [DECat]).

ragullós (< rogallós, derivat de rogall, format sobre "roc, roga < RAUCU): Empordà, Mallorca (DCVB).

ragullar (< rogallar): Rosselló, Mallorca (DCVB).

satorrani (< soterrani < SUBTERRANEUM): Mallorca, Menorca. Doc.: a. I640 (Mesquida).

balongera 'tipus de dansa' (< balangera): Vilanova de Sau (Plana de Vic) (Moran, Comentari 22).

llangonissa (< llonganissa [normatiu, encara avui valencià]< LUCANICIA, homonimitzat amb llong [DECat]): català nordoccidental, balear (DCVB);

tamborella (< tombarella): Moià (opcional) (ALDC).

treboli $(<$ terboli $<$ torbelin < torbenin < TURBININU [DECat]). General i normatiu.

\section{El fenomen invers: de vocal central a vocal velar}

El fenomen invers de velarització de [0] o [a] en [o] (o [u]) no és desconegut. Es dóna en alguns pocs casos, condicionats sempre pel context. En dono uns exemples:

1) d' assimilació vocálica: terròs > turròs, fagony > fogony, tartuga > tortuga;

2) d'assimilació consonàntica; a) amb labial: mastí > mustí, DAMASCU $>$ domàs, encepegar > ensopegar, refresc > rofresc, safata > sofata; b) amb la velar $l$ : alzina > olzina, salpàs > solpàs, palitxó > politxó, a més dels casos ben coneguts d'*àvel > àvol, escàndel $>$ escindol, etc. 
El nombre de casos és molt limitat -en absolut comparable al fenomen que estudiem aquí-i sempre impulsat per l'assimilació.

\section{L'aportació dels diacronistes}

Els diacronistes no han concedit gaire espai a l'estudi d'aquest fenomen.

Tomàs Forteza (II, n.f) s'ocupa del canvi de o en e a esperó i verdolaga i cita com a vulgars de Mallorca variants com veluntat, redolar, remerol, elor $i$ Bonesaires.

P. Fouché (Phoriétique 74) exemplifica el canvi en rossellonès amb casos de dissimilació i de diferenciació. Entre els primers cita l'ant. redon (mod. rodon), rellotge, securs, secutre (< SUCCUTERE), acupar, faburt (< fr. faubourg), Hanorat ( $\mathrm{ja}$ a. 1393), ensacutri (dins all ensacutri 'all silvestre'), la un i explica les variants rosselloneses xicolata i quinyol 'tascó' (< CUNEOLU) a partir de les formes dissimilades xacolata i "quenyol. Quant a la diferenciació, esmenta plaurà 'plourà', maurà 'mourà'.

Griera (Gramàtica 51), referint-se al català antic, afirma que en la llengua medieval es dóna "esporàdicament a per $o$ " i cita tres exemples: ganfanons 'gonfanons', prametets 'prometets' i safragànea 'sufragània', sense intentar explicar el fenomen..

Badia ( 163 ) al ludeix, d'un costat, al pas $o>e$, exemplificat amb rellotge (< (HO)ROLOGIU), redó (< ROTUNDU), pregon (< preon < prevon < PROFUNDU) i sacós (< socós < SUCCURSU); de l'altre, parla de la diferenciació ou $>$ eu del tipus [pl'wra] (<ploură).

Moll (Gramàtica 95-96), a més de citar els casos de dissimilació rellotge, redó i remor (<RUMORE), es refereix al pas $o>a$ en certs mots recolzant-se en les paraules de Menéndez Pidal: "ayudando oscuras asimilaciones o disimilaciones a cierta preferencia otorgada a la a inicial como vocal más clara"; i cita navalla (< NOVACULA), llambric (< "LUMBRICU) i calostte (< COLOSTRU); a més, atribueix a una confusió dels prefixos $\mathrm{OB}-\mathrm{i} \mathrm{AD}-$, en benefici d'aquest, l'ant, ancegar (< OBCAECARE), aturar (<OBTURARE) i acubar (OCCUPARE).

Coromines s'ha ocupat d'aquest canvi incidentalment $i$ en passatges diversos de les seves obres. La tipificació segons les seves causes és:

1) Casos de diferenciació degut a contacte d'/o/ amb una altra vocal velar: lo $u n>$ la $u n$.

2) Casos de dissimilació $/ 0 / \ldots / 0 / \rightarrow / 2 / \ldots$ /o/ : la Donzell $(<$ lo Donzell), la Gornal (< lo Gomal), la Molso(r) < lo Molso(r) (EDL, 
II, 120-12I); igualment interpretava marfui 'marfull, mosquit' des de l'hipotètic i difícilment acceptable mord-fui (literalment 'mossega i fuig') (DECat s.v, marfull; Veny "Els noms").

3) Casos de dissimilació $/ 0 / . . / o ́ / \longrightarrow /$ a $/ \ldots / o ́ /$ a bé $/ 0 / \ldots /$ ú $/ \rightarrow$ /a/.../ú/: llagosta < LOCUSTA, calostre < colostre, caluix < coluix, Calonge < Colonge (DECat, III, 200a, II, 65I, a).

4) Casos provocats pel "costat de l (palpis, clatell, altrança, si mel convé) (Coromines 1972, 178, n. 30; DECat, s.v. falç). En un altre lloc addueix altres exemples: a altra hora, aldà, Besalú, Alvan, aufrany (DECat, s.v. hora).

Duarte i Alsina, atents a les lleis més generals d'evolució fonètica, fan cas omis del fenomen.

Recasens (Fonètica) és el qui més ha reflexionat sobre el canvi, del qual recull diversos exemples -del centenar que té recollits-i que considera condicionat:

1) per dissimilació: a) en posició pretònica, del tipus xacolata, saroll, Palònia, la un ; amb "possibilitat de dissimilació anticipatòria davant de $/ 1 /$, , com gatim ;

b) en posició posttònica, del tipus tòrtara;

c) per contacte amb vocal velar, del tipus maurà 'mourà';

d) per veïnatge d'una $l$, del tipus alrada (dels exemples cal eliminar salcit 'sarzit', del qual solcit és una modificació);

2) per assimilació davant vocal baixa (/a/), mitjana central ([ə]) o mitjana anterior $([\mathrm{e}],[\varepsilon])$ del tipus fermatge.

\section{Comentari}

Gran part d'aquests exemples han estat incorporats a les llistes precedents. Tanmateix, cal fer-hi alguns comentaris.

Els exemples de Griera no són objecte de cap interpretació. $\mathrm{He}$ considerat safragànea -variant que no he trobat enlloc més-com una assimilació a la tònica /á/ i ganfanons com una dissimilació de la tònica /ó/; prametets podria obeir a una substitució de prefix: tanmateix, atès que Moll l'introdueix amb el sentit de 'posar davant o abans' (< PRAEMITTERE) i que, d'altra banda, no disposem del context, he prescindit d'aquesta variant.

La preferència per la vocal a inicial com a vocal més clara, invocada per Moll, a través de l'autoritat de Menéndez Pidal, pot haver influit en el cas de canvis antics (navalla, aturar, llagosta, etc.), però no en els més 
tardans, sobretot si pertanyen al català oriental (xacolata, aliva, alicorn, magut, sacós, babó, etc.), amb articulació de vocal neutra, sense l'atribut de la claredat. Pel que fa a l'ètim d'acubar (< OCCUPARE), Coromines, tenint en compte la seva modernitat i la seva àrea restringida, prefereix partir d'un derivat de cup, opinió que crec força acceptable.

Entre els exemples elencats pels anteriors estudiosos figuren formes amb $e$, resultat d'una dissimilació antiga, com ho demostra la lingüistica romànica i la pronúncia occidental: redó (fr. ant. reond, cast. redondo, port. redondo), esperó (fr. éperon), prégon, remor, verdolaga (afegim-hi lledó, petó, enterbolar, escurir). En els casos de redó, remor i rellotge podria considerar-se l'influx del prefix re-, com apunta Moll.

Pel que fa a Coromines, remarquem la bona troballa respecte a la dissimilació dels topònims del tipus la Donzell (< lo Donzell). Interessant també la consideració de la influència del context de lvelar en el canvi (tipus palpis), recollida també per Recasens, actuant com a agent dissimilador: el nombre de casos s'acreix amb les meves llistes (palvora, estaló, galfó, calbot, flacolera, Calonge, saldar, altrança, palmons, alrada, Palònia, alor, etc.). Cal, tanmateix, tenir en compte que la major part d'aquests casos es poden explicar per altres factors (dissimilació, assimilació, fonosintaxi, especialment en posició inicial absoluta [a ultrança > altrança ]).

Recasens és el qui presenta una tipologia més estructurada del canvi, que grosso modo he seguit en la meva classificació. Tanmateix, no he considerat cap apartat amb possible influència de la velar $l$; no veig el tipus gatim com a casos de "dissimilació anticipatòria" sinó en tot cas d'assimilació parcial; i he considerat la possible assimilació a /e/, / $\varepsilon$ / dins "altres casos," tot i que confesso que no veig clara aquesta acció.

\section{Conclusions}

Gràcies a obres com el Diccionari català-valencià-balear, al Diccionari etimològic $i$ complementari de la llengua catalana, a l'Onomasticon Cataloniae i als materials inèdits de l'Atles lingüistic del domini català, he pogut recollir més de tres-cents trenta mots afectats per la centralització de o (i $u$ ). Una xifra no gens menyspreable. Cal, però, reconèixer que la major part pertanyen al camp de l'onomàstica 0 constitueixen variants dialectals. I encara aquestes, sotmeses a certes restriccions. Unes porten l'estigma del vulgarisme (saldat 'soldat', prapaganda, etc.), fins i tot idiolèctic (candort 'cóndor'); d'altres han estat drenades a la llengua antiga (lambard); d'altres, només apareixen en pronúncia relaxada (trabar); d'altres vénen marcades pel seu localisme (banito, magró, etc.); d'altres posseeixen un caràcter opcional (llabarro / llobarro). 
Però interessa remarcar que quaranta-dos dels mots comuns (si fa no fa el $15 \%$ ) pertanyen a la llengua normativa:

abassegar, alicorn, ansí, arguenell, armoll, aturar, aufrany, avalotar (es-), baldar, baldador, bavarada, barromba, boga-ravell, calbot, calostre, caluix, caramull (acaramullar), catxel, clatell, claveguera, encegar, enfarfegar, esbaldregar (esbaldrec, esbaldregat, esbaldregada), estaló, estapolany, llagosta, llamàntol, llambric, llaor, mandonguilles, navalla, palpis, parçoner, pasterol, patarc, pató, patracol, ramarol, salamó, samontà, tafaner, taronja.

I tampoc manquen topònims com Alaró, la Barroca, sa Calobra, Calonge, Magòria.

Davant una xifra prou generosa, per descomptat amb les limitacions assenyalades, estaríem temptats de parlar d'una "nova llei fonètica del català." Cal reconèixer que, donades les característiques del canvi (variabilitat geogràfica, opcionalitat, context, etc.), seria exagerat arribar a aquesta conclusió. Potser podríem parlar d'una "llei secundària" o "llei menor," com diria el nostre homenatjat, entesa com una notable tendència del català (més l'oriental que l'occidental) a centralitzar la /o/ (eventualment la /u/) àtona, especialment en posició inicial. Aquesta tendència ve afavorida quantitativament en primer lloc per la dissimilació i en segon lloc per l'assimilació, tot i que en alguns casos les dues fan acció conjunta. S'afegeixen puntualment a aquests dos factors fenòmens d'homonimització (tipus palpis <-polpis $\mathrm{x}$ palpar) i, en el cas de la inicial absoluta, de fonosintaxi (tipus una olor $\rightarrow$ una lor $\rightarrow$ un (a) alor $\rightarrow$ alor). Els casos de metàtesi (llangonisa <- llonganissa) poden tenir com a mòbil aquesta tendència.

A la vista de la força d'aquest canvi cobren més credibilitat propostes etimològiques originals, que devem al talent de J. Coromines, com abassegar (< OBCAECARE) i enfarfegar (< "enfr'ofogar).

El fet que afecti un nombre alt d'unitats lèxiques, una quarantena de les quals sốn mots comuns, reconeguts per la llengua estàndard, mereix que les gramàtiques històriques li dediquin almenys un apartat.

JOAN VENY

UNIVERSITAT DE BARCELONA INSTITUT D'ESTUDIS CATALANS 


\section{BIBLIOGRAFIA}

Aguiló, Tomás. Rondaya de rondayes, 1817. Ed. Joan Mas i Vives. Palma de Mallorca. 2a ed. 18I5.

Aguiló Dicc. $=$ Diccionari Aguiló. Materials lexicogràfics aplegats per Marian Aguiló i Fuster, revisats i publicats sota la cura de Pompeu Fabra 1 Manuel de Montoliu. Barcelona, 1914-34.

Amigö, Ramon. Toponimia de Vila-seca de Solcina $i$ del seu terme municipal, Vila-seca / Salou, 1978

-.-. Toponímia del terme municipal de Vilallonga de Ter, Barcelona, 1979.

--. Noms de lloc i de persona del terme de Prades, Reus-Prades, 1985.

--. Materials per a l'estudi dels noms de lloc i de persona, $i$ renoms, del terme de Reus. 1988.

Alomar, Antoni Ignasi. L'armament $i$ la defensa a la Mallorca medieval. Terminologia. Palma de Mallorca, 1995.

BADIA, Antoni M, Gramática bistórica catalana. Barcelona, I95I.

BENEJAM, Joan. Ciutadella veya. Recorts d'un quant temps enrera, Ciutadella. 1909.

BIETE, Vicenç. Toponimia de Cabacers i el seu terme. Barcelona, 1983. BOTET, Renat. Vocabulario rossellonès, Perpinyà, 1997.

CABRERA, Maria Rosario. El món mariner a Dénia, Alacant, 1997.

CARDus, Maria. "Sobre la pèrdua de la 's final a la Garrotxa." Miscel-lania Aramon i Serra. Estudis de llengua i literatura catalanes oferts a R. Aramon i Serra en el seu setantè aniversari. Vol. 3, Barcelona, 1983. 39-42.

Carreté, Ramon. Onomàstica de Balsarery. Tesi doctoral, U de Barcelona, 1996.

Centelles, Jacques. Les dedans de la mer. Perpinyà, I979.

Coll, Pep. El parlar del Pallars. Tremp, 199r.

Cotón, Germà. "Valenciano calbot "golpe en la nuca'." Revista Valenciana de Filologia, 3 (I953): 211-I4.

Coromines, Joan. Tópica hespérica. Vol. II. Madrid, 1972.

--. Entre dos llenguatges. Vol. II. Barcelona: Curial, 1976.

DuARTE, Carles, Allex Alsina. Gramática bistòrica del català. 3 vols. Curial, 1984-86.

FABRA, Pompeu. Ensayo de gramática de catalár modemo. Barcelona. $198 \mathrm{r}$.

FABREgAS, Esteve, Carme Rebollo. La cultura tradicional i el parlar de Lloret. Lloret de Mar, 1989.

Figuera, Manel. "El parlar de Cerdanya, Característiques gramaticals $i$ aspectes lèxics més importants." Ceretania (Puigcerdà) (a998): 203-26

FONT, Antoni. Fons verborum Barcelona, 1637. 
FONT, Bartomeu. Historia de Llucmajor. Vol. 5. Mallorca, 1986.

FORTEZA, Tomàs. Gramática de la lengua catalana. Palma de Mallorca, I9I5.

ForTunY, J. B. La parla d'Ós de Balaguer. Tesi de Llicenciatura, U de Barcelona, 1983.

FOUCHE, Pierre. Phonétique historique du roussillonnais, Toulouse, 1924. GaLLART, Josep. Llengüies en contacte a Perpinyà a finals del s. XIX. El vocabulari de les Catalanades d'Un Tal. Tesi doctoral, U Autònoma de Barcelona, 1994.

Gimeno, Lluís. Atles lingüistic de la diòcesi de Tortosa, Barcelona: Institut d'Estudis Catalans, 1997.

GRANDó, Carles. "Vocabulari rossellonès." Miscel-lània Fabra. Recull. de treballs de lingüistica catalana $i$ romànic dedicats a Pompen Fabra, Barcelona, 1943 (edició facsímil, Barcelona, 1998).

GrIERA, Antoni, Gramàtica històrica del català antic. Barcelona, 1931.

---. Tresor de la llengua, de les tradicions $i$ de la cultura popular de Catalunya. Barcelona, 1935 (2a ed., 1966).

GuLsoY, Joseph. Estudis de gramàtica històrica. València-Barcelona, 1993. Huguet, Alícia. Catàleg d'espècies d'interès pesquer a Catalunya. Barcelona, 1991.

LAMARCA. Ensayo de un diccionario valenciano-castellano. Valencia, 1839.

Lle.enart, Jordi, Josep M. Camarasa. La pesca a Catalunya el 1722 segons un manuscrit de Joan Salvador i Ricra. Barcelona, 1987.

Llopis, Isabel. Inventari i estudi dels noms de lloc $i$ de persona de l'antic terme d'Albarca (el Priorat). Barcelona, 1994.

LlorCA, Francesc X. El llenguatge mariner de la Marina. Tesi doctoral, U d'Alacant, 1998.

LUNA, Xavier. "Les vocals tòniques a l'Alt Empordà." Annals de l'Institut d'Estudis Empordanesos 28 (i995): 267-303.

Manent, Albert. Toponímia de l'Aleixar i del seu terme. Tarragona, 1962 .

MarTi Mestre, Joaquim. El 'Llibre d'Antiguitats' de la Sen de València. València-Barcelona, 1994.

Mascaró Pasarius, Josep. Corpus de toponimia de Mallorca. Palma de Mallorca, 1952-62.

Mrsouida, Joan A. El tractat del salitre (Palma 1640). Estudi històric i lingüistic d'un text quimic del segle XVII. Palma de Mallorca, 1996. Mila I Fontanals, Manuel. "Catalán contemporáneo," Estudios de lengua catalana. Barcelona, 1875 .

MiLlAS, Manuel. Els microbios. València, 1884.

MirAvitules, Joan. Curs superior de català 1934-1935 professat per Pompen Fabra. Andorra la Vella, 1971.

Moll, Francesc de B. Gramatica bistórica catalana. Madrid, 1952.

-... Els llinatges catalans. Palma de Mallorca, 1982. 
MonNer, Antoni. Toponímia de Gandesa i el seu terme municipal, Tarragona.

Moran, Josep. "Notes de toponímia antiga del Pla de Barcelona." Estudis de Llengua $i$ Literatura Catalanes. Vol. I (Homenatge a Josep M. de Casacuberta. Vol. I), 1980. 103-15.

MOREU-REY, Enric. "Toponímia del terme, actual i pretèrit, de l'Albiol." Anuario de Filología 2 (1976): 447-530.

--- Renoms, motius, malnoms i noms de casa. Barcelona, $198 \mathrm{r}$.

--. Antroponimia. Historia dels nostres prenoms, cognoms i renoms. Barcelona, I99I.

--. "Comentari lingüístic." Grup de Recerca Folklòrica d'Osona, Cançons i tonades tradicionals de la comarca d'Osona, Sèrie I. Vol. 2., Barcelona, 1994. 21-26.

Onomasticon $=\mathrm{J}$. Coromines (director), Onomasticon Cataloniae, Barcelona, 1989-97.

PANYELLA, Vinyet. Recull de motius de la vila de Sitges (segles XVI-XX). Sitges, 1987.

PERE, Ramon, Ramon Amigó. Onomàstica del terme municipal d'Ulldemolins, Barcelona, 1997.

PlazA, Carme. La parla de la Conca de Barberà. Tarragona, I996.

PRATS, Joan. "Toponímia del terme i del poble d'Arbolí." Revista Catalana de Geografia 1, 3 (1980): 447-528.

Puigrós, M. Antònia. “Estudi fonètic del parlar de Manacor." Randa 14 (Homenatge a Joan Veny) (1998): 129-44.

Pujades, Jeroni. Dietari, a cura de Josep M. Casas Homs. Barcelona, 1975.

RAMIS, Juan. Specimen animalium, Vegetabilium et Mineralium in insula Minorca frequentiorum. Maó, 1814.

Recasens, Daniel. Estudi lingüistic sobre la parla del Camp de Tarragona. Barcelona, 1985.

---, Fonètica descriptiva del català, Barcelona, 1991 (2a ed., 1996 per la qual cito).

RELXAC, Baldiri. Instruccions per a l'ensenyança de minyons, (v. 1748). Vol. 2. Ed. S. Marquès i A. Rossich. Girona, $198 \mathrm{I}$.

RicHou, Montserrat. Aproximació a la bistòria d'Argentona (segles XIII-XV). Argentona, 1987.

Riera, Carles. Caracterització de l'idiolecte d'un parlant de Moià. Barcelona, 1993.

RierA, Manel. Estudi de la llengua catalana a Andorra. Barcelona, 1992.

Ros, Carles. Diccionario valenciano-castellano. València, 1764.

SALA, Ernesta. El parlar de Cadaqués. Girona, 1983.

SegurA, Carles (1998): El parlar d'Elx a estudi: aproximació a una descripció. Elx. 
Veny, Joan. "Paralelismos léxicos en los dialectos catalanes," Revista de Filología Española 42 (1958-59): 91-149; 43 (1960): $117-202$.

-... "Etimologia ictionímica: el català petarc 'crenilabrus scina'." Ed. J. L. Melena, Symbolae Ludovico Mitxelena Septuagenario oblatae. Vitoria, 1985. 753-761.

.... "L'ètim de merita 'fredeluga'; entre l'arabisme i l'onomatopeia." Estudis de Llengua $i$ Literatura Catalanes. Vol. 12 (Miscel-lània Antoni M. Badia Margarit. Vol, 4). Barcelona, 1986.37-61.

... "Catxel 'Cardium edule', un nou mossarabisme del català." La Corona d'Aragó $i$ les llengües romàniques. Miscel-lània d'Homenatge per a Germà Colón, Tübingen, 1989. 463-475.

.... Mots d'abir i mots d'avui. Barcelona, 1991.

---. Dialectologia filològica. Barcelona, 1993.

-...- "La importación del fonema /x/ en catalán." Revista Española de Lingüística 24 (1994): 1-19.

-.-. "Dialectologia contrastiva." Jornades de la Secció Filològica de l'Institut d'Estudis Catalans a Mallorca. Barcelona-Palma, 1997.

..-. "Els noms catalans del mosquit." Revista de Filología Románica (Memoria-Homenaje a Pedro Peira Soberón) 14.2 (1997): 487-501.

--. Els parlars catalans. Sintesi de dialectologia. Mallorca, 1998, 12a ed.

-. Aproximació al dialecte eivissenc. Mallorca, 1999.

-.-. "La interferència occitana en l'obra epidemiològica d'Antoni Girauld (1587)." Mélanges Allières (en premsa), 1999.

\section{SIGLES}

ALDC $=$ Joan Veny - Lídia Pons (directors). Atles Lingüístic del Domini Català. Barcelona: Institut d'Estudis CatalansUniversitat de Barcelona (en curs d'elaboració).

DCVB $=$ Antoni M. Alcover. Francesc de B, Moll. Diccionari catalàvalencià-balear. Palma de Mallorca, 1930-62.

DECat $=$ Joan Coromines. Diccionari etimològic $i$ complementari de la llengua catalona, Barcelona: Curial, 1980-1986.

DIEC = Institut d'Estudis Catalans, Diccionari de la Llengua Catalana, Barcelona, Palma de Mallorca, València, 1995.

FEW $=$ Walter von Wartburg. Französisches Etymologisches Wörterbuch. Bonn, Leipzig-Berlin, Basilea, des de 1928.

$\mathrm{LEI}=$ Max Pfister, Lessico etimologico italiano, Wiesbaden (en curs de publicació).

$\mathrm{LMP}=$ Manuel Alvar (coordinador): Léxico de los marineros peninsulares, Madrid, 1985-1989.

SOBI $=$ Societat d'Onomàstica. Butlletí interior, Sant Adrià de Besòs. 